\title{
Latitudinal and seasonal variability of gravity-wave energy in the South-West Indian Ocean
}

\author{
F. Chane-Ming, D. Faduilhe, and J. Leveau \\ Laboratoire de l'Atmosphère et des Cyclones, Université de la Réunion, Météo-France, CNRS, UMR 8105, La Réunion, \\ France
}

Received: 24 August 2007 - Revised: 29 November 2007 - Accepted: 7 December 2007 - Published: 2 January 2008

\begin{abstract}
Vertical temperature profiles obtained by radiosonde and Raman lidar measurements are used to investigate a climatology of total energy density of gravity waves (GW) in the Upper Troposphere (UT) and the Lower Stratosphere (LS) from 1992 to 2004 above Mahé $\left(4^{\circ} \mathrm{S}, 55^{\circ} \mathrm{E}\right)$, Tromelin $\left(15^{\circ} \mathrm{S}, 54^{\circ} \mathrm{E}\right)$ and La Réunion $\left(21^{\circ} \mathrm{S}, 55^{\circ} \mathrm{E}\right)$ located in the tropical South-West Indian Ocean. The commonly used spectral index value $(p \approx 5 / 3)$ of the intrinsic frequency spectrum is used for calculating estimated total energy density in the UT and LS. Estimated total energy density provides good estimation of total energy density in the LS but underestimates total energy density by one half in the UT above Mahé and Tromelin probably due to the activity of near-inertial frequency waves. Estimated total energy density reveals a strong seasonal variability as a function of latitude and convection as an evident active source of GW activity in the LS in austral summer. Above La Réunion, a semi-annual GW activity is observed in the LS with the signature of the subtropical barrier in the UT. Moreover, radiosondes and Raman lidar provide consistent GW surveys in the UT/LS at heights $<23 \mathrm{~km}$ above La Réunion.
\end{abstract}

Keywords. Atmospheric composition and structure (Middle atmosphere - composition and chemistry; Troposphere - composition and chemistry)

\section{Introduction}

Tropical atmospheric Gravity-Waves (GW) play a key role in exchanges between atmospheric layers in terms of transport of momentum and atmospheric constituents (Holton, 1975; Ehhalt et al., 1983). Theories, observations and models support that GW contribute significantly to the mean general circulation in the middle atmosphere and to the atmospheric thermal structures up to $80-\mathrm{km}$ heights. Because of

Correspondence to: F. Chane-Ming

(fchane@univ-reunion.fr) the broad band scales of GW produced in the lower atmosphere, GW are not yet correctly resolved in numerical models. Local and global observations of GW are still needed to improve their parameterization in weather forecast and climate models. To model observed GW patterns in simple models of middle atmosphere, recent investigations focused on the characteristics of GW sources and/or GW spectral parameters near sources in the Upper Troposphere (UT) and the Lower Stratosphere (LS). Hence, daily high-resolution radiosonde data archived by meteorological services reveal to be useful for $\mathrm{GW}$ climatologies in the lower atmosphere (Allen and Vincent, 1995). Global maps of GW activity have been produced using CHAMP/GPS radio occultation soundings and CRISTA measurements in the stratosphere (Tsuda et al., 2000; Ern et al., 2004). GW climatologies using highresolution meteorological radiosonde data have been mainly made above continental stations such as above Australia from June 1991 to May 1992 (Allen and Vincent, 1995) and above the United States from 1998 to 2002 (Wang and Geller, 2003). Few references exist over the tropical ocean where convection is the major GW source (Beres et al., 2002). For instance, recent radar observations revealed the characteristics of highly convective zone in regard to induced GW in the UTLS in the vicinity of Bay of Bengal region and Indonesian region (Dhaka et al., 2002, 2005). GW activity in the LS was recently explored with radiosondes in the tropical Pacific in November to December 2001 (Sato et al., 2003), above the South-East Indian Ocean at Cocos Islands $\left(12^{\circ} \mathrm{S}, 97^{\circ} \mathrm{E}\right)$ between September 1992 and June 1998 (Vincent and Alexander, 2000) and above Darwin area in October to December 2001 (Tsuda et al., 2004). The present study provides a GW climatology of total energy density over the tropical SouthWest Indian Ocean basin above Mahé $\left(4^{\circ} \mathrm{S}, 55^{\circ} \mathrm{E}\right)$, Tromelin $\left(15^{\circ} \mathrm{S}, 54^{\circ} \mathrm{E}\right)$ and $\mathrm{La}$ Réunion $\left(21^{\circ} \mathrm{S}, 55^{\circ} \mathrm{E}\right)$ islands in the UT/LS. The monthly-mean and latitudinal variation are retrieved from radiosonde and Raman lidar measurements from 1992 to 2004.

Published by Copernicus Publications on behalf of the European Geosciences Union. 

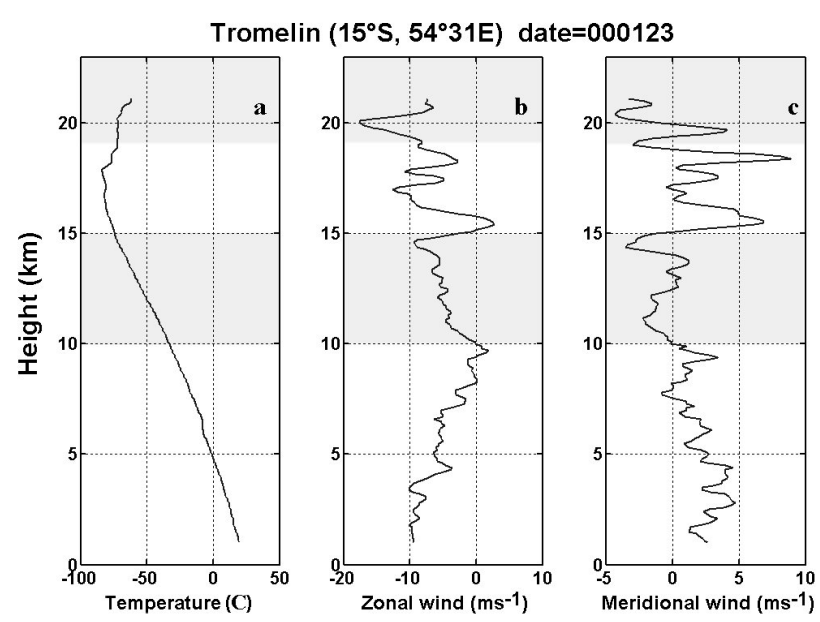

Raman Lidar temperature profiles date: 000123(15h42-20h42)

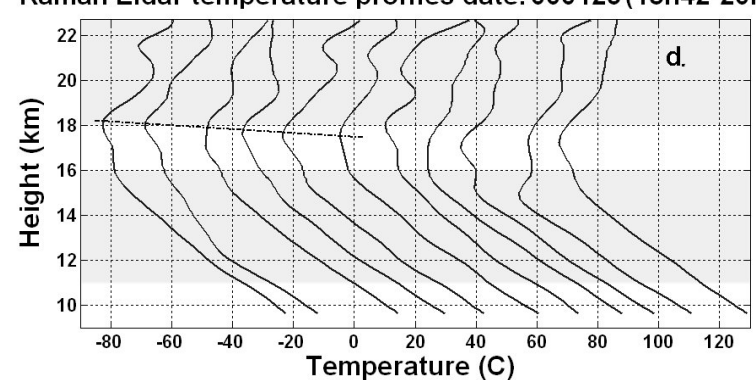

Fig. 1. Vertical profiles of (a) temperature, (b) zonal wind and (c) meridional wind at Tromelin Island and (d) successive 30-min integrated vertical profiles of temperature with $150-\mathrm{m}$ spatial resolution produced by a Raman lidar at La Réunion between 1542 and 2042 on 23 January 2000. The dash-dotted lines and grey areas indicate a downward phase progression and height ranges respectively for gravity-wave analysis.

\section{Experimental data}

Mahé $\left(4^{\circ} \mathrm{S}, 55^{\circ} \mathrm{E}\right)$, Tromelin $\left(15^{\circ} \mathrm{S}, 54^{\circ} \mathrm{E}\right)$ and La Réunion $\left(21^{\circ} \mathrm{S}, 55^{\circ} \mathrm{E}\right)$ islands are located in the South-West Indian Ocean at almost the same longitude. Mahé is the main island of Republic of Seychelles with a surface of $148 \mathrm{~km}^{2}$ rising to $905 \mathrm{~m}$ near the equator. Tromelin is a $1 \mathrm{~km}^{2}$ sandy desert island peaking at $7 \mathrm{~m}$ above the sea level (Chane-Ming et al., 2002). La Réunion with a surface of $2512 \mathrm{~km}^{2}$ is located at the border of the tropical belt under tropical and subtropical conditions respectively during austral summer and during austral winter (Chane-Ming et al., 2000b). The dataset includes GPS radiosonde data at Mahé and Tromelin and Väisälä RS80 ozonesonde and Raman lidar measurements at La Réunion.

Analyzed GPS radiosonde data consist of vertical profiles of temperature, horizontal winds and relative humidity with $100-\mathrm{m}$ vertical resolution and with accuracies of $0.1 \mathrm{~K}$ and $<1 \mathrm{~ms}^{-1}$ for the temperature and the horizontal wind respectively. $75 \%$ of GPS radiosondes daily-launched at Tromelin
(Mahé) at 1200 UT reached the height of $23 \mathrm{~km}(25 \mathrm{~km})$ from January 1998 to December 2003 (Table 1).

At La Réunion, 150-m sampled temperature vertical profiles are produced by ozonesondes launched every 2 weeks from 1992 to 1999 and weekly after 1999 in the framework of the Southern Hemisphere Additional Ozonesonde (SHADOZ) and the Network for Detection of Atmospheric Composition and Change (NDACC, previously NDSC) programs (Baray et al., 2006).

The dataset of La Réunion is completed with 30-min integrated temperature profiles produced by a Raman lidar with 150-m vertical resolution from January 1999 to May 2004 at 1830-1900 UT. A similar algorithm used for Rayleigh lidar technique is applied on the vibrational nitrogen Raman return signal at $607 \mathrm{~nm}$ recorded during clear sky condition and low aerosol loading to derive temperature profiles (Keckhut et al., 1990; Faduilhe et al., 2005). Short-scale structures with vertical wavelengths $<1 \mathrm{~km}$ have been filtered out to reduce temperature uncertainties due to photon noises of the instrument. In contrast vertical resolution of radiosonde measurements enables us to get information on GW down to a vertical wavelength of $200 \mathrm{~m}$. Lidar temperature mean standard deviations are $1.27 \mathrm{~K}(2.64 \mathrm{~K})$ and mean differences in temperature with radiosonde data of La Réunion from January 1999 to May 2004 are $-0.27 \mathrm{~K}(1.6 \mathrm{~K})$ at heights of $18-23 \mathrm{~km}(11-16 \mathrm{~km})$.

Figure 1 shows examples of vertical profiles of radiosonde and lidar measurements on 23 January 2000 respectively at Tromelin and La Réunion. Fourier spectra indicate the presence of wavelike structures with vertical wavelengths of $1.6 \pm 0.3 \mathrm{~km}$ and $2.75 \pm 1.7 \mathrm{~km}$ at Tromelin above the tropopause. The hodograph of horizontal wind perturbations (not shown) visualizes GW signatures with upward propagating wave energy characterized by an elliptical structure of anti-cyclonic nature. Structures with vertical wavelengths of $1.9 \pm 0.5 \mathrm{~km}$ and $3.2 \pm 1.2 \mathrm{~km}$ are observed during 1542 and 2042 UT above La Réunion. Successive vertical temperature perturbation profiles suggest downward vertical phase propagation estimated at about $-0.34 \mathrm{~ms}^{-1}$ at heights between 17 and $20 \mathrm{~km}$ from 1542 and 1842 UT. Such typical structures are characteristics of GW previously observed in the upper stratosphere above La Réunion (Chane-Ming et al., 2000a).

\section{Procedure of analysis}

The total energy density $\left(\mathrm{E}_{T}\right)$ defined in the threedimensional model of GW power spectrum (Fritts and VanZandt, 1993) is chosen as a measure for GW (Vincent and Alexander, 2000):

$E_{T}=\frac{1}{2}\left(\overline{u^{\prime 2}}+\overline{v^{\prime 2}}+\overline{w^{\prime 2}}+\frac{1}{2} \frac{g^{2}}{N^{2}} \overline{\hat{T}^{\prime 2}}\right)=\mathrm{KE}+\mathrm{PE}$

Where $u^{\prime}, v^{\prime}, w^{\prime}$ are respectively the zonal, meridional, and vertical components of wind, $\hat{T}^{\prime}$ is the temperature 
Table 1. Location of sites, time period, and height ranges used to derived gravity-wave energy density in the UT/LS above Mahé, Tromelin and La Réunion. $N_{\mathrm{UT}}$ and $N_{\mathrm{LS}}$ are numbers of analyzed high-quality vertical profiles respectively in the UT and LS. RS means radiosonde.

\begin{tabular}{lccccc}
\hline & Location & Year & UT height $(\mathrm{km})$ & LS height $(\mathrm{km})$ & $N_{\mathrm{UT}} / N_{\mathrm{LS}}($ Time $)$ \\
\hline Mahé (RS) & $4^{\circ} \mathrm{S}, 55^{\circ} \mathrm{E}$ & $1999-2003$ & $10-15$ & $18-23$ & $1058 / 592(0000 \mathrm{UT})$ \\
& & & & & $1149 / 811(1200 \mathrm{UT})$ \\
Tromelin (RS) & $15^{\circ} \mathrm{S}, 54^{\circ} \mathrm{E}$ & $1998-2003$ & $10-15$ & $19-25$ & $1231 / 940(1200 \mathrm{UT})$ \\
La Réunion (RS) & $21^{\circ} \mathrm{S}, 55^{\circ} \mathrm{E}$ & $1992-2002$ & $10-15$ & $19-26$ & $222 / 206(0500 \mathrm{UT})$ \\
La Réunion (Lidar) & $21^{\circ} \mathrm{S}, 55^{\circ} \mathrm{E}$ & $1999-2004$ & $11-16$ & $18-23$ & $49 / 84(1830$ UT-1900 UT) \\
\hline
\end{tabular}

perturbations normalized by the unperturbed temperature background, $g$ is the gravitational acceleration, $N$ is the buoyancy frequency, the overbar means an unweighted average over height, $\mathrm{KE}$ and PE are kinetic and potential energies respectively. Kinetic energy is calculated without the vertical wind component which is much smaller than the horizontal components and not measured by radiosonde and Raman lidar. Assuming the linear theory of GW, the total energy density can be estimated as a function of temperature only (Allen and Vincent, 1995).

$E_{T}=\frac{1}{B_{0}} C_{I n} \frac{g^{2}}{N^{2}} \overline{\hat{T}^{\prime 2}}$

$B_{0}=(p-1) \frac{f^{p-1}}{1-\tilde{f}^{p-1}} ;$

$\mathrm{C}_{I n}=\frac{f^{1-p}}{1-\tilde{f}^{2}}\left(\frac{1-\tilde{f}^{p-1}}{p-1}-\frac{1-\tilde{f}^{p+1}}{p+1}\right)$

where $p$ is the spectral index for the intrinsic frequency spectrum (VanZandt, 1982) and $\tilde{f}=f / N$ is the ratio of the inertial frequency $\mathrm{f}$ to the buoyancy frequency $N$. The energy spectrum scales are assumed to be of the form $\omega^{-p}$ from $f$ to $N$ with a constant value of $p \approx 5 / 3$ provided by many observations in the middle atmosphere.

Table 1 gathers some information about the dataset used for the GW analysis in the UT/LS for the 3 sites of observation. Lower levels of selected height ranges are chosen to avoid possible tropopause effects on the temperature perturbations. Selected height ranges enable us to analyze GW with vertical wavelengths less than $5 \mathrm{~km}$ from temperature and wind perturbation profiles which are retrieved from raw profiles using a 2nd order polynomial fit (Allen and Vincent, 1995).

\section{Gravity wave energy density}

Climatologies of GW energy density usually refer to the potential energy (PE) or the estimated total energy (hereinafter noted $\mathrm{Et}_{T}$ ) instead of the total energy density (hereinafter noted $\mathrm{Et}_{T+V}$ )(Allen and Vincent, 1995; Tsuda et al., 2000; Ratnam et al., 2004). $\mathrm{Et}_{T+V}$ is estimated with both temperature and horizontal wind observations (Eq. 1) while $\mathrm{Et}_{T}$ is computed with only temperature observations (Eq. 2). Figure 2 shows monthly and monthly mean $\mathrm{Et}_{T+V}$ values as a function of $\mathrm{Et}_{T}$ values in the UT and the LS above Mahe and Tromelin. Linear least squares regression fits indicate that $\mathrm{Et}_{T}$ values in the UT underestimate $\mathrm{Et}_{T+V}$ values by a factor coefficient of 2 (1.7) with an offset of $2.6 \mathrm{~J} \mathrm{~kg}^{-1}\left(1.4 \mathrm{~J} \mathrm{~kg}^{-1}\right)$ for the monthly mean values above Mahé (Tromelin). In the LS, $\mathrm{Et}_{T}$ monthly mean values provide a good estimation of $\mathrm{Et}_{T+V}$ monthly mean values with a factor coefficient of about 0.96 with an offset of 3.05 and $-0.87 \mathrm{~J} \mathrm{~kg}^{-1}$ above Mahé and Tromelin, respectively. In addition, the correlation coefficients between $\mathrm{Et}_{T}$ and $\mathrm{Et}_{T+V}$ values are $>0.8$ in the UT/LS. From relations between $\mathrm{Et}_{T}$ and $\mathrm{Et}_{T+V}$ observed above Mahé and Tromelin, the activity of GW estimated energy density above La Réunion is investigated in comparison with those above Mahé and Tromelin in the UT/LS (Fig. 3a and b). Thus Fig. 3a indicates that the total energy density actually varies between $2 \mathrm{~J} \mathrm{~kg}^{-1}$ and $15 \mathrm{~J} \mathrm{~kg}^{-1}$ in the UT with an annual variability of which maximum values are observed during austral winter from June to October above Mahé and from May to September above Tromelin. The variation of energy density above La Réunion reveals the presence of two peaks in June and in October for the two radiosonde datasets (1992-2002 and 1999-2002). The peak intensity is about $1.6-2$ times larger than the second minimum of $2.5-3 \mathrm{~J} \mathrm{~kg}^{-1}$ observed in July to September in mid-winter. Energy density values obtained with Raman lidar data agree well with those of radiosonde data with similar magnitudes from January to May and from August to December. In addition the rotary-spectra analysis (Vincent et al., 1997) indicates that about $55-63 \%$ and $40-50 \%$ of the energy propagate upward in summer and winter respectively above Tromelin and Mahé in the UT.

In the LS, energy values decrease poleward (Fig. 3b). A strong annual cycle is observed above Mahé peaking during austral summer. The seasonal cycle becomes semi-annual above La Réunion with a second peak in August-September caused by mid-latitude conditions in winter (Allen and Vincent, 1995). In contrast with observations in the UT, $71 \%$ (78\%) and $63 \%(77 \%)$ of the energy propagate upward respectively in summer and winter above Mahé (Tromelin). This suggests that GW sources are located in the troposphere. 


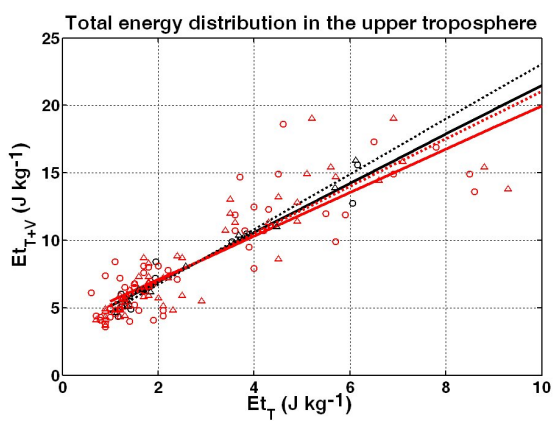

(a)

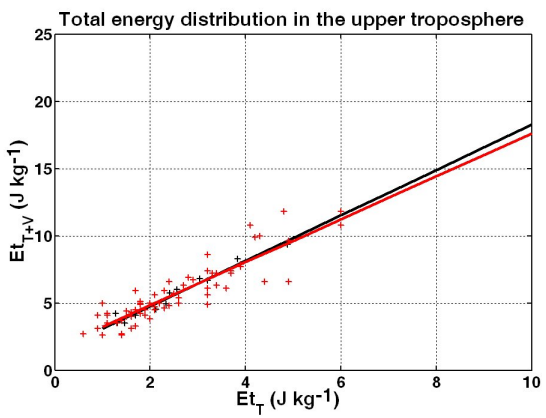

(b)

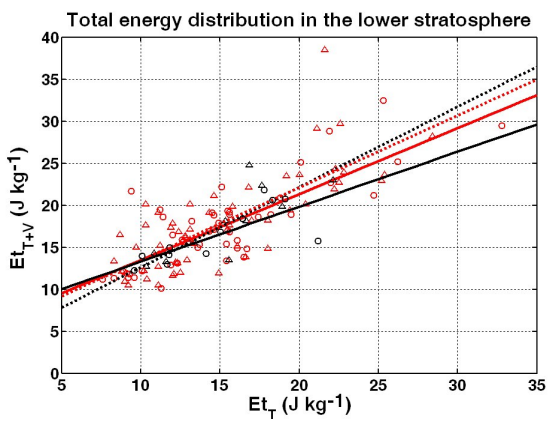

(c)

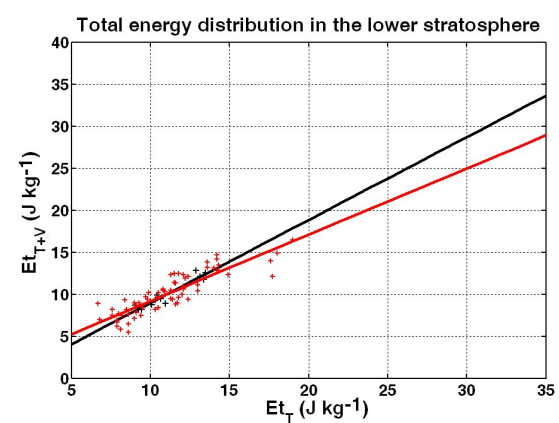

(d)

Fig. 2. Monthly and monthly-mean wave energy density derived from temperature and wind $\left(\mathrm{Et}_{T+V}\right)$ versus those derived from temperature only $\left(\mathrm{Et}_{T}\right)$ (a) above Mahé at 00:00 UT (red and black circles, respectively) and at 12:00 UT (red and black triangles) and corresponding least-squares regression lines for Mahé at 00:00 UT (red and black dashdot lines respectively) and 12:00 UT (red and black solid lines respectively) and (b) above Tromelin at 1200 UT (red and black crosses respectively) and corresponding least-squares regression lines (red and black solid lines respectively) in the UT. (c) and (d) Same as panel (a) and (b) but for the LS, respectively.

For the 3 sites, maxima in summer are well-correlated with indices of convection such as Outgoing Longwave Radiation (OLR) data and in situ and Tropical Rainfall Measuring Mission (TRMM) rain distribution. Correlation values between monthly series of energy density and these indices of convection are larger than 0.7 above Mahé and Tromelin. Figure 3b also shows a consistent seasonal evolution of GW energy at 00:00 UT and 12:00 UT and evidence of a diurnal variability of above Mahé with a peak at 12:00 UT in March. The peak is correlated with the strength of the convective activity at this time as previously observed over Taiwan $\left(25^{\circ} \mathrm{N}\right.$, $121^{\circ}$ E) (Ratnam et al., 2004).

Above La Réunion, energy density values and the monthly trend are consistent for the two datasets (1992-2002 and 1999-2002) and lidar data in the LS. The activity of GW energy density from lidar data also peaks in summer. Uncertainties of $\mathrm{Et}_{T}$ with $95 \%$ confidence level are less than $0.6 \mathrm{~J} \mathrm{~kg}^{-1}\left(1.3 \mathrm{~J} \mathrm{~kg}^{-1}\right)$ and less than $1 \mathrm{~J} \mathrm{~kg}^{-1}\left(3 \mathrm{~J} \mathrm{~kg}^{-1}\right)$ for radiosonde and lidar data respectively in the UT (LS). Figure $3 a$ and $b$ reveal that the seasonal evolution of GW energy in the UT/LS above Tromelin agrees well with that above Mahé and La Réunion due to its intermediate location between the two other sites.

\section{Discussion and conclusions}

The seasonal variability of GW energy density over the tropical South-West Indian Ocean is consistent with those produced by Allen and Vincent (1995) and Wang and Geller (2003) with maxima of stratospheric energy density during low-latitude wet season and the midlatitude winter. The largest gravity wave activities at $20-30 \mathrm{~km}$ were generally located around the equator between $25^{\circ} \mathrm{N}$ and $25^{\circ} \mathrm{S}$ (Wang and Geller, 2003). A semiannual variability with the two regimes is also observed at intermediate latitudes. Allen and Vincent (1995) first revealed a strong peak in energy density in the troposphere during winter in contrast with the peak observed in the LS during summer. The peak in the troposphere does not coincide with particular meteorological events or geographic characteristics. Wang and Geller (2003) suggests that energy density values are virtually uncorrelated. The average time-scale, perturbations induced other tropical processes and selective filtering during GW horizontal and vertical propagation (Alexander, 1998) might affect observations in the UT. Thus specification of GW sources in the troposphere is needed to understand the troposphere-stratosphere differences in total energies. In 
addition, Alexander et al. (2002) examines the poleward decrease of energy as a natural consequence of the latitudinal variation of the Coriolis parameter.

Vertical short-scale structures with vertical wavelengths of $1-5 \mathrm{~km}$ produced by GW and large-scale advection were analyzed in the UT/LS above La Réunion using ozonesonde data (Chane-Ming et al., 2000b). Dominant GW sources are revealed to be convection in summer and the subtropical jet in winter. Laminae induced by quasi-horizontal large-scale motions are observed to be 1.3 times more numerous than GW structures during winter in the UT. This suggests that the two peaks of energy density observed in June and in October correspond to the transition between tropical and subtropical conditions at the subtropical barrier with the presence of small-scale vertical structures induced by horizontal large-scale motions. In summer, tropical cyclones are severe convective phenomena which directly affect Tromelin and La Réunion. They reveal to be significant sources of GW in the UT/LS above the south-west Indian basin (Chane-Ming et al., 2002).

The global distribution of PE values using GPS Occultation data at heights $<25 \mathrm{~km}$ shows that large $\mathrm{PE}$ values $>6 \mathrm{~J} \mathrm{~kg}^{-1}$ are mostly localized at low latitudes between $25^{\circ} \mathrm{N}$ and $25^{\circ} \mathrm{S}$ centered on the equator and enhanced over regions of deep convection such as over landmass of Africa and islands in the Indian Ocean (Tsuda et al., 2000; Ratnam et al., 2004). A region of large energy density $\left(>7 \mathrm{~J} \mathrm{~kg}^{-1}\right)$ is centered over Madagascar with an extension over Mozambique, Tromelin and La Réunion at $20-30 \mathrm{~km}$ heights from November to February. As opposed the energy activity is zonally symetric with $\pm 7^{\circ}$ width over Indian Ocean and spreads over Mahé. Thus large difference in energy values observed at Mahe and Tromelin suggests a possible contribution of other equatorial waves such as Kelvin waves at latitudes between of $\pm 10^{\circ}$ (Tsuda et al., 2000). Indeed the correlation between worldwide map of National Oceanographic and Atmospheric Administration (NOAA) OLR with observed GW activity in the stratosphere shows two active regions of tropical deep convection over Indian Ocean (the African convection and the maritime convection) in austral summer (Jiang et al., 2004). Moreover the Indian monsoon might be a possible source of tropical waves over Mahé in austral winter. GPS CHAMP satellite data at longitudes between $80^{\circ} \mathrm{E}$ and $180^{\circ} \mathrm{E}$ and at latitudes between $30^{\circ} \mathrm{N}$ and $30^{\circ} \mathrm{S}$ identifies a bell-shaped distribution of PE energy density symmetric around the equator. Assuming that the ratio $\mathrm{KE} / \mathrm{PE}$ is equal to the spectral index $p(5 / 3)$, consistent total energy magnitudes are obtained in the LS at latitudes of Mahé, Tromelin and La Réunion, respectively (Tsuda et al., 2004).

The maximum of GW density over Cocos Islands $\left(12^{\circ} \mathrm{S}\right.$, $97^{\circ} \mathrm{E}$ ) is about 1.8 times larger than that observed above Tromelin in summer LS although the two sites are located at similar latitudes in the Indian Ocean (Vincent and Alexander, 2000). As opposed it is comparable with that observed

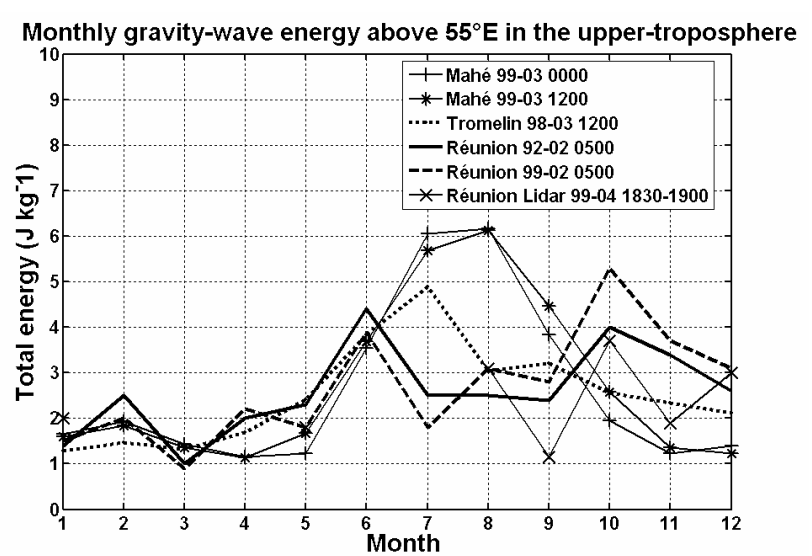

(a)

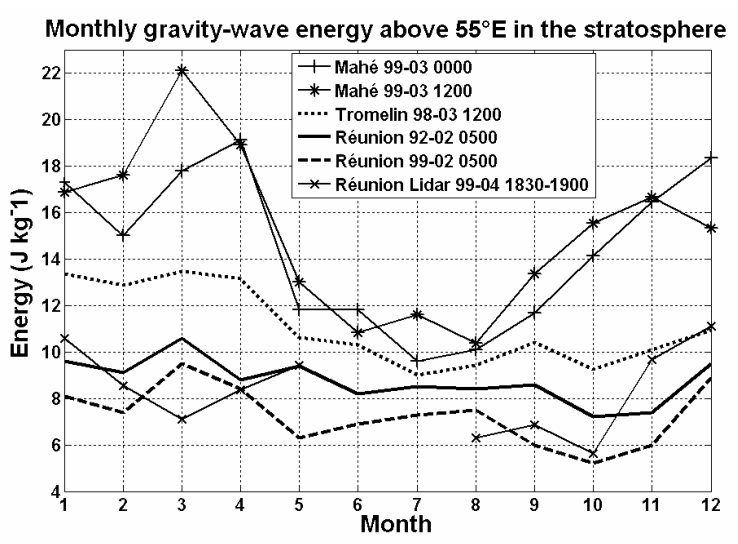

(b)

Fig. 3. (a) Estimated monthly-mean wave energy density from radiosonde measurements in the upper troposphere above Mahé at 00:00 UT and 12:00 UT, Tromelin at 12:00 UT and Réunion at 05:00 UT and from Raman lidar data above La Réunion at 18:30 UT-19:00 UT. (b) Same as panel (a) but for the LS.

above Mahé for which the Quasi-Biennal Oscillation signature is also apparent in the stratospheric zonal wind data. Thus GW distribution over Indian Ocean depends on latitudinal and longitudinal location of observation sites due to the presence of different localized active convective regions over the Indian basin. In conclusion, a first climatology of GW total energy density is investigated above the tropical South-West Indian Ocean at longitude of $55^{\circ} \mathrm{E}$. The seasonal variability of total energy density is strongly dependent on the latitudinal location of the observation site. Results complete previous GW climatologies on energy density values above the tropical South-West Indian Ocean and provide useful references for future studies on the energy contribution of dominant GW sources. In addition, comparison between total energy density and the estimated total energy density above Mahé and Tromelin reveals that the commonly 
used value of the spectral index $(p=5 / 3)$ underestimates the total energy density in the UT by one half. Barat and Cot (1992) and Nastrom et al. (1997) noticed a discrepancy between observed and expected ratio of GW kinetic to potential energies with observed values greater than 5 in the LS. Nastrom et al. (1997) hypothesized that near-inertial frequency waves might be responsible of an excess of GW kinetic energy in the LS. More recently, intrinsic-frequency spectra derived from quasi-lagrangian measurements reveal that such large values are due an enhancement of wave activity at nearinertial frequencies (Hertzog et al., 2002).

Evolution and intensities of total energy density above the 3 sites are consistent in the UT and in the LS. Moreover, the signature of the subtropical barrier is clearly observed on the seasonal activity of total energy density in the UT above La Réunion. Similar total energy density values resulted from both radiosonde and Raman lidar datasets prove that the Raman lidar installed at La Réunion can produce continuous night-time GW surveys near the subtropical barrier in the UT/LS at heights $<23 \mathrm{~km}$.

Acknowledgements. This work was performed with the financial support of La Région Réunion/L'Europe and the Centre National de la Recherche Scientifique. The authors thank the radiosonde and lidar teams of La Réunion, Météo-France and the Wyoming University for datasets.

Topical Editor F. D'Andrea thanks S. Dhaka and another anonymous referee for their help in evaluating this paper.

\section{References}

Alexander, M. J.: Interpretations of observed climatological patterns in stratospheric gravity wave variance, J. Geophys. Res., 103(D8), 8627-8640, 1998.

Alexander, M. J., Tsuda, T., and Vincent, R.A.: Latitudinal variations observed in gravity waves with short vertical wavelengths, J. Atmos Sci., 59(8), 1394-1404, 2002.

Allen, S. J. and Vincent, R. A.: Gravity wave activity in the lower atmosphere: Seasonal and latitudinal variations, J. Geophys. Res., 100(D1), 1, 1327-1350, 1995.

Barat, J. and Cot, C.: Wind shear rotary spectra in the atmosphere, Geophys. Res. Lett., 19, 103-106, 1992.

Baray, J.-L., Leveau, J., Baldy, S., et al.: An instrumented station for the survey of ozone and climate change in the southern tropics, J. Environ. Monitor., 8, 1020-1028, 2006.

Beres, J. H., Alexander, M. J., and Holton, J. R.: Effects of tropospheric wind shear on the spectrum of convectively generated gravity waves, J. Atmos. Sci., 59(11), 1805-1824, 2002.

Chane-Ming, F., Molinaro, F., Leveau, J., Keckhut, P., and Hauchecorne, A.: Analysis of gravity-waves in the tropical middle atmosphere over La Reunion Island $\left(21^{\circ} \mathrm{S}, 55^{\circ} \mathrm{E}\right)$ with Lidar using wavelet techniques, Ann. Geophys., 18(4), 485-498, 2000a.

Chane-Ming, F., Molinaro, F., Leveau, J., Keckhut, P., Hauchecorne, A., and Godin, S.: Vertical short-scale structures in the upper tropospheric-lower stratospheric temperature and ozone at La Reunion Island $\left(20.8^{\circ} \mathrm{S}, 55.3^{\circ} \mathrm{E}\right)$, J. Geophys. Res., 105(D22), 26857-26 866, 2000b.

Chane-Ming, F., Roff, G., Robert, L., and Leveau, J.: Gravity wave characteristics over Tromelin island during the passage of cyclone Hudah, Geophys. Res. Lett., 29(6), 1094, doi:10.1029/2001GL013286, 2002.

Dhaka, S. K., Choudhary, R. K., Malik, S., Shibagaki, Y., Yamanaka, M. D., and Fukao, S.: Observable signatures of a convectively generated wave field over the tropics using Indian MST radar at Gadanki (13.5 $\left.5^{\circ}, 79.2^{\circ} \mathrm{E}\right)$, Geophys. Res. Lett., 29(18), 1872, doi:10.1029/2002GL014745, 2002.

Dhaka, S. K., Yamamoto, M. K., Shibagaki, Y., Hashiguchi, H., Yamamoto, M., and Fukao, S.: Convection-induced gravity waves observed by the Equatorial Atmosphere Radar $\left(0.20^{\circ} \mathrm{S}\right.$, $\left.100.32^{\circ} \mathrm{E}\right)$ in Indonesia, Geophys. Res. Lett., 32, L14820, doi:10.1029/2005GL022907, 2005.

Ehhalt, D. H., Roeth, E. P., and Schmidt, U.: On the temporal variance of stratospheric trace gas concentrations, J. Atmos. Chem., 1, 27-51, 1983.

Ern, M., Preusse, P., Alexander, M. J., and Warner, C. D.: Absolute values of gravity wave momentum flux derived from satellite data, J. Geophys. Res., 109, D20103, doi:10.1029/2004JD004,752, 2004.

Faduilhe, D., Keckhut, P., Bencherif, H., Robert, L., and Baldy, S.: Stratospheric temperature monitoring using a vibrational Raman lidar. Part 1 in: Aerosols and ozone interferences, J. Environ. Monitor., 7(4), 357-364, 2005.

Fritts, D.C., and VanZandt, T.E.: Spectral estimates of gravity waves energy and momentum fluxes, I, Energy dissipation, acceleration, and contraints, J. Atmos. Sci., 50(22), 3685-3694, 1993.

Hertzog, A., Vial, F., Mechoso, C. R., Basdevant, C., and Cocquerez, P.: Quasi-Lagrangian measurements in the lower stratosphere reveal an energy peak associated with near-inertial waves, Geophys. Res. Lett., 29(8), 1229, 10.1029/2001GL014,083, 2002.

Holton, J. R.: The dynamic meteorology of the stratosphere and mesosphere, Meteor. Monographs, vol. 15, p. 37, American Meteorological Society, Boston, 1975.

Jiang, J. H., Wang., K. B., Goya, K., Hocke, K., Eckermann, S. D., Jun Ma, D. L., Wu, D. L., and Read, W. G.: Geographical distribution and interseasonal variability of tropical deep convection: UARS MLS observations and analyses, J. Geophys. Res., 109, D03111, doi: 10.1029/2003JD003756, 2004.

Keckhut, P., Chanin, M. L., and Hauchecorne, A.: Stratosphere temperature measurement using Raman lidar, Appl. Opt., 29, 51825186, 1990.

Nastrom, G. D., VanZandt, T. E., and Warnock, J. M.: Vertical wavenumberspectra of wind and temperature from highresolution balloon soundings over Illinois, J. Geophys. Res., 102, 6685-6701, 1997.

Ratnam, V. M., Tetzlaff, G., and Jacobi, C.: Global and seasonal variations of stratospheric gravity wave activity deduced from the CHAMP/GPS satellite, J. Atmos. Sci., 61(13), 1610-1620, 2004.

Sato, K., Yamamori, M., Ogino, S.Y., Takahashi, N., Tomikawa, Y., and Yamanouchi, T.: A meridional scan of the stratospheric gravity wave field over the ocean in 2001 (MeSSO2001), J. Geophys. Res., 108(16), 4491, doi:10.1029/2002/2002JD003219, 2003. 
Tsuda, T., Nishida, M., Rocken, C., and Ware, R. H.: A Global morphology of gravity wave activity in the stratosphere revealed by the GPS occultation data (GPS/MET), J. Geophys. Res., 105(6), 7257-7273, 2000.

Tsuda, T., Ratnam, M. V., May, P. T., Alexander, M. J., Vincent, R. A., and MacKinnon, A.: Characteristics of gravity waves with short vertical wavelengths observed with radiosonde and GPS occultation during DAWEX (Darwin Area Wave Experiment), J. Geophys. Res., 109(D20), D20S03, doi:10.1029/2004JD004946, 2004.

VanZandt, T. E: A universal spectrum of buoyancy waves in the atmosphere, Geophys. Res. Lett., 9, 575-578, 1982.
Vincent, R. A., Allen, S. J., and Eckermann, S. D.: Gravity wave parameters in the lower stratosphere, in Gravity wave processes: Their parameterization in global climate models, edited by Hamilton, K., 7-25, Springer-Verlag, 1997.

Vincent, R. A. and Alexander, M. J.: Gravity waves in the tropical lower stratosphere: An observational study of seasonal and interannual variability, J. Geophys. Res., 105(D14), 17971-17982, 2000.

Wang, L. and Geller, M.A.: Morphology of gravity wave energy as observed from 4 years (1998-2001) of high vertical resolution U.S. radiosonde data, J. Geophys. Res., 108, 4196-4205, 2003. 